\title{
Empirical perspectives on species borders: from traditional biogeography to global change
}

\author{
Camille Parmesan, Steve Gaines, Laura Gonzalez, Dawn M. Kaufman, Joel Kingsolver, A. Townsend Peterson and \\ Rafe Sagarin
} Parmesan, C., Gaines, S., Gonzalez, L., Kaufman, D. M., Kingsolver, J., Peterson,
A. T. and Sagarin, R. 2005. Empirical perspectives on species borders: from traditional
biogeography to global change. - Oikos 108: $58-75$.

In this paper we will outline several empirical approaches to developing and testing hypotheses about the determinants of species borders. We highlight environmental change as an important opportunity - arguing that these unplanned, large-scale manipulations can be used to study mechanisms which limit species distributions. Our discussion will emphasize three main ideas. First, we review the traditional biogeographic approach. We show how modern analytical and computer techniques have improved this approach and generated important new hypotheses concerning species' range determinants. However, abilities to test those hypotheses continue to be limited. Next we look at how the additions of temporal data, field and lab experimentation, biological details and replication, when applied to systems that have been the subject of classical biogeographic studies, have been used to support or refute hypotheses on range determinants. Such a multi-faceted approach adds rigor, consistency and plausible mechanisms to the study of species ranges, and has been especially fruitful in the study of climate and species' ranges. Lastly, we present an alternative avenue for exploration of range-limiting mechanisms which has been underutilized. We argue that carefully designed comparisons and contrasts between groups of species or systems provide a powerful tool for examining hypotheses on species' borders. The seasonality hypothesis as an explanation for Rapoport's rule serves as a model of this approach. A test is constructed by comparing patterns of seasonality and range size among marine and terrestrial systems. The seasonality hypothesis is not supported.

C. Parmesan and L. Gonzalez, Integrative Biology, Univ. of Texas, Austin, TX 78712, USA (parmesan@mail.utexas.edu)._-S. Gaines,Ecology,Evolution and Marine Biology, Univ. of California at Santa Barbara, Santa Barbara, CA 93106, USA. - D. M. Kaufman, Biology, Kansas State Univ., Manhattan, KS 66506, USA. - J. Kingsolver, Biology, Univ. of North Carolina, Chapel Hill, NC 27599, USA. - A. T. Peterson, Natural History Museum, Univ. of Kansas, Lawrence, KS 60045, USA. - R. Sagarin, Environmental Health Sciences, Univ. of California, Los Angeles, CA 90095, USA.

\footnotetext{
"There is one important area of biology whose problems I have hardly touched on in this book: this is ecology. ... I felt that any attempt to treat (it) would tend to confuse the picture."
}

John Maynard Smith (1986), The problems of biology

Since before ecology was a recognized discipline, biologists have been intrigued by the simple question of why species occur where they do. Why are some species confined to small areas while others span the globe? As far back as the early 1700s, Tournefort recognized that plants tend to form distinct zones, thus spawning

Accepted 8 June 2004 
another suite of questions concerned with species' associations and community integrity. Answers to these questions hinge heavily on the determinants of borders of species distribution, thus building the foundation for much of classical ecological literature (Grinnell 1917, Orton 1920, Setchell 1920, Wulff 1950, Andrewartha and Birch 1954, Hutchinson 1957). As the 20th century progressed, classical biogeography receded from the forefront of ecological research. The inherent correlational nature of the data did not fit with a newer emphasis on careful hypothesis testing under controlled conditions. Small scale, carefully controlled experimentation began to dominate ecological literature. Yet, still, the fundamental question of why species are distributed as they are remained a scientific puzzle (Rosen 1988, Webb and Bartlein 1992, Hoffmann and Blows 1994, Brown et al. 1996, Gaston 2000).

In the last 10 years, events outside of science have sparked a revival of interest in this question, not only among scientists but also in the public and governmental sectors. Global warming, exotic invasions, land-use change with commensurate habitat fragmentation and pollution are modifying the distributions of many species. Ecologists are being asked to assess current impacts on natural systems and to predict responses to continued anthropogenic pressures in the next century. Biology has progressed in understanding how environmental factors affect species distributions, but abilities remain limited to predict responses to scenarios of future global environments. Many of the questions surrounding human impacts are concerned with effects on biodiversity and species' distributions and, hence, fall within the field of biogeography. Historically, this field was largely a description of patterns but much progress has occured in recent years. Are there additional avenues which can be exploited to improve the predictive powers of biogeographic research? Can this discipline be molded to meet the demands presented by the public and policy communities?

In this paper, we begin with a brief review of empirical approaches to the study of species distributions - the growth of these approaches through time, and some of their continuing limitations in elucidating specific determinants of range limits. Anthropogenic changes challenge the study of 'pure' ecological interactions by providing a background onslaught of forces which confound natural change. But, by performing manipulations on a grand scale, these same changes also provide an opportunity for post-hoc tests of hypotheses on species distributions.

Because much of historical biogeography has focused on natural climate as a driver of species' ranges, here we emphasize how studies of the effects of anthropogenic climate change have improved our understanding of the drivers of species' distributions. The impacts of recent climate change have given greater insight into the extent to which climate limits species' ranges, both at the coarse scale of global distribution and the fine scale defining specific species' boundaries.

Finally, we present a conceptually simple but relatively unexplored avenue for examining hypotheses of species' distributions through the use of carefully selected comparisons and contrasts between groups of species or systems. This synthetic, large scale approach could provide a powerful tool for more rigorous development and testing of hypotheses on causal limits of species borders.

\section{Biogeographic approaches}

\section{The Grinnellian approach}

"An explanation of the distributional limits of a species must
be rooted in the geographic facts of environment as much as in
the physiological facts of adaptability" Caughley et al. 1988

The traditional approach studying species' distributions proceeds in two main steps, which principally follow Grinnell (1917). First, the geographic distribution of a species is overlaid with the geographic distribution of environmental factors, to identify which environmental factor(s) coincide with a species border. Although these extrinsic factors are often aspects of the physical environment (e.g. temperature, moisture, soil type), they may also be aspects of the species' biotic environment (e.g. the distribution of predators, competitors, parasites, resources, vegetation communities). Second, some biological property of the species is identified (e.g. reproductive rate, metabolic rate or freeze tolerance) that could explain the observed coincidence between the species border and the environmental factor. As an example, the northern limit of the winter distribution of the Eastern Phoebe in eastern North America coincides with the $-4^{\circ} \mathrm{C}$ isotherm of average minimum temperature in January (Root 1988a). Root (1988b) proposed that this coincidence may be explained by energetic limitations on food intake and metabolic requirements for survival at temperatures below $-4^{\circ} \mathrm{C}$ for this species.

Modern statistical analyses, such as principal components, discriminant function, multiple regression and logistic regression, have enabled the determination of complex suites of climatic variables which correlate with the range boundaries for given species (e.g. BIOCLIM software, Nix 1986). The advent of Geographic Information System software and digitized datasets has allowed the expansion of these analyses to include non-climatic variables such as soils and topography. 
To attain more realism, models were developed which allowed for local adaptation (i.e. for adaptation to different habitat niches occurring in different parts of the range), as well as for different factors operating to limit the species' range at different range boundaries (e.g. the northern vs the southern range edges). Such models include classification and regression trees (CART) which use a binomial decision process that develops separate rules to define local habitats throughout the range. Complex multivariate or logistic regression models are often used in conjunction with other techniques to derive the best predictive variables.

A sophisticated software program - Genetic Algorithm for Rule-set Prediction, or GARP (Stockwell and Noble 1992) takes yet another approach. GARP uses artificial intelligence techniques to allow the program to 'learn' which variables provide the most information on species occurrence as it works its way through a particular data set. This algorithm uses multiple avenues to decisions regarding niche limits, permitting much more flexibility in inferences. This kind of approach allows for more realistic, quantitative multi-factor analyses, while maintaining statistical rigor. GARP has demonstrated a high level of predictive power in cross validation tests in which it has successfully modeled habitable ecological spaces for three species with a considerable degree of accuracy (Peterson and Cohoon 1999).

\section{Confounding factors and spurious statistics}

As successful as the traditional Grinnellian niche approach has been at correlating the boundaries of species' ranges with a variety of environmental factors, there remains some question as to whether these statistical associations identify the true determinants of species borders. There are several reasons to exercise caution when interpreting the results of species-environment correlations. First, the chance for spurious correlations is high since the number of potential environmental correlates is enormous. For temperature alone, one could examine the averages or the extremes, the lows or the highs, individual values or accumulated values (e.g. degree days), the monthly, seasonal or yearly patterns, etc. If other variables are added (e.g. precipitation), or if functions of multiple environmental variables are used, the probability of spurious correlations becomes very high. Thus, though such correlations are often strong, these studies often suffer from overprediction (Peterson and Vargas 1993).

Further, many environmental metrics covary spatially. Therefore, a given variable may be a good predictor of the location of a species border solely because it covaries with the true determinant(s). For example, the correlation of temperature and divergent ocean currents on either side of barriers at Cape Hatteras and Point Conception (east and west coasts of the USA, respectively). The two sides of each barrier harbor very different marine intertidal communities and the barriers themselves constitute nothern or southern borders for many species. The physical landscape features and ocean currents that help to generate steep temperature gradients also act as barriers to dispersal of intertidal organisms. Therefore, because they coincide, it cannot be determined from simple correlations whether temperature, divergent ocean currents, or a physical barrier is responsible for the demarcation between northern and southern speciesgroups.

\section{A shifting environment and complex boundary dynamics}

\begin{abstract}
"Environments are forever changing ... with relative rapidity they circulate about over the surface of the earth, and the species occupying them are thrust or pushed about, herded as it were, hither and thither."
\end{abstract}

Joseph Grinnell, 1924

In spite of the sophisticated application of modern quantitative approaches to traditional biogegraphy, two implicit assumptions may introduce error in interpretation of distributional data on range limits. The first is that the current distribution of a species is representative of its basic habitat requirements; the second is that these requirements remain relatively invariant through time (discussed in Pearson and Dawson 2003).

This second assumption of ecological conservatism has been predicted by numerous theoretical studies (Brown and Pavlovic 1992, Holt and Gaines 1992, Houston and McNamara 1992, Kawecki and Stearns 1993) and has recently gained some empirical support (Jablonski 1987). Peterson et al. (1999) studied the distributions of 37 pairs of sister taxa (74 species) of birds, mammals and butterflies in Mexico. They found that habitat requirements derived from analysis of the distribution of one species could be used to predict the distribution of its sister taxon with remarkable accuracy. However, an analyses of range sizes among con-generic species on different continents indicated that ecological requirements are conserved within genera of herbaceous perennials, but not within other plant groups (e.g. trees or shrubs; Rickleffs and Latham 1992). Until more empirical work is available, it is unclear which systems are likely to conserve their ecological niche through time, and which are more labile evolutionarily.

How sensitive are the model results to the assumption that the realized distribution represents the fundamental distribution? In the study of world-wide distribution of biomes, this assumption is probably not critical. It is 
likely that responses to large scale dramatic environmental change, such as $4^{\circ} \mathrm{C}$ global warming scenarios, can be modeled with sufficient accuracy for many broad questions to be addressed (Huntley 1991). However, at a smaller scale, such as trying to predict the effects of another $1^{\circ}$ warming in Great Britain, the complexities of boundary determinants for species become more important for accurate predictions (Beerling 1993, Hill et al. 2003).

A recent study by Thomas et al. (2004) attempted to estimate the numbers of species at risk from extinction under varying climate change scenarios. They reported a high variance among estimates, some of which may be due to real difference in sensitivity among taxa or regions, but much of which may also be due to differences among models. For example, model estimates for the high range climate change scenario with full dispersal varies from $8 \%$ for European plants to $85 \%$ for Australian birds. This high variance does not obscure the main message of the paper - i.e that projected climate change will lead to many species' extinctions, with risk of extinction correlated with the degree of global temperature rise. But, the imprecision associated with bioclimate models (discussed above) make it difficult to rigorously quantify extinction risk without additional mechanistic understanding of the drivers of species distributions.

Recent studies have served as a reminder that attributes other than fundamental physiological tolerances can drive local range boundaries. The influence of competition on species boundaries is illustrated in a particularly elegant microcosm experiment by Davis et al. (1998). They first determined the separate fundamental niches for three species of Drosophila along a thermal gradient (imposed on connected bottles in a laboratory). A subsequent series of manipulations showed that the realized niches were actually determined by competitive and host-parasite interactions, resulting in expansion and contraction of 'range edges' away from where the species could theoretically exist. Further, the interactions themselves were affected by the exact dimensions of the thermal gradient (the values of the temperature extremes). At initial temperature conditions, D. subobscura's distribution amongst the bottles was shifted into the cooler end of the bottle series by competition with congenerics at the warmer end. With simulated 'global warming' conditions (i.e. shifting the end-points of the temperature range), the observed distribution became almost identical to that expected from temperature tolerance alone.

There is a class of models which begins to address these problems of context-dependent responses by explicitly studying changes of distributions through time, and allowing for different capacities of response among different species. These models use dynamic simulation to incorporate biological attributes such as population growth rates and dispersal abilities. (e.g. SGDVM, the Sheffield dynamic global vegetation model). It is possible that future additions to this approach could add in differential competitive abilities as well.

As another complication, rapid local evolution has been shown to occur in natural systems. In the case of two species of Australian fruit fly, local hybridization led to novel adaptations which allowed range expansion with no concomitant environmental change (Lewontin and Birch 1966). At study sites in Spain, RodríguezTrellis and Rodríguez (1998) documented evolution of population frequencies of temperature-sensitive chromosome inversions in D. subobscura in a direction consistent with regional warming trends. Clearly, then, one possible response to this particular environmental change is evolutionary (local adaptation) rather than ecological (shifting borders). To predict the most likely response, something must be known about spatial patterns of natural selection and gene flow, and about the capacity of the target taxon for evolutionary response (Hoffmann and Blows 1994, Kirkpatrick and Barton 1997, Davis and Shaw 2001). Several studies suggest that effect of both genetic constraints and asymmetrical gene flow are intensified close to species' borders (Antonovics 1976, Hoffmann and Blows 1994, Garcia-Ramos and Kirkpatrick 1997).

\section{Temporal data}

\section{Insights from paleontological and modern studies}

Studies which track distributional changes through time can be extremely useful to point to underlying causative factors of range limits. Environmental changes can be quantified and used as a 'natural experiment' against which distributional changes occurring over the same time frame can be mapped. When proposed competing factors are not correlated, likely causal mechanisms determining range limits can then be inferred from observing which external changes elicit a response in the organisms.

Paleontological records of range changes associated with major climatic shifts such as the glacial to interglacial transitions have been widely used both to highlight the strong correlation of climatic variables with species' ranges and to make predictions about responses of species' ranges to present day climatic warming. Classic studies have come out of pollen data for forest communities (Huntley and Birks 1983, Davis and Zabinski 1992) and fossils of beetles (Coope 1995, Ashworth 1997, Morgan 1997, Ponel 1997). Over time spans from Holocene to $140000 \mathrm{ybp}$, range shifts of hundreds of kilometres, and as much as $2,000 \mathrm{~km}$, have been documented for individual species associated with mean temperature changes of $4^{\circ}$ to $8^{\circ} \mathrm{C}$ over as little as 
500 years. Such striking, repeatable patterns clearly indicate that climate is a strong rangelimiting factor.

More recent records have been used to look for similar, long term responses in wildlife to climatic change over this past century. The quality and resolution of the data through time varies among studies. At one extreme is 'snapshot' data of an ecological system at widely disparate points in time. For example, Sagarin et al. (1999) and Barry et al. (1995) recensused intertidal transects near Monterey, California. from 1993 to 1996 that were first censused in 1931. Abundances of over 100 intertidal invertebrates were measured. They found that, compared to the earlier survey, abundances of nearly all southern species had increased significantly while abundances of nearly all northern species decreased. These changes occurred over a 60 year period of significant warming in nearshore sea temperatures and did not show any trend towards returning to the earlier state over the duration of the recent census period. Holbrook et al. (1997) found similar range related shifts over the past 25 years for kelp forest fish communities of southern California. Southern species have greatly increased their proportionate dominance of community composition at the expense of more northern species.

To study response to relatively rapid shifts in temperatures, more complete time series data are preferable. A sophisticated analysis was possible with a 70-year time series of marine species' abundances and sea temperatures from Britain (Southward et al. 1995). Using yearly (often monthly) data, this study found responses to be very rapid. Warm water species increased in abundance and cold water species declined during short term periods of ocean warming (1920-1960; 1981-1995) while the opposite occurred during cooling periods (1960-1981).

Parmesan and Yohe (2003) conducted a global synthesis of these types of long-term studies estimated that out of 460 species that have altered their local abundances or geographic distributions, $81 \%$ have done so in directions predicted as a response to recent climate change (Table 1). Their meta-analysis of a subset of 99 species showed that, on average, species have moved northward by $6.1 \mathrm{~km} /$ decade (or upslope by $6.1 \mathrm{~m}$ decade $^{-1}$ ). Observed changes are varied, but span diverse taxa and geographic regions (reviewed in detail by IPCC 2001a, Parmesan in press, Parmesan and Galbraith 2004). Changes in fish and invertebrate communities along the California coast are mirrored in copepod communities of the North Atlantic, as midAtlantic species moved off the coast of Great Britain and North Sea species moved towards Iceland (Beaugrand et al. 2002). Changes in distributions along segments of range edges show general expansion into traditionally cooler habitat for amphibians and birds in Costa Rica (Pounds et al. 1999), birds in the U.K. (Thomas and Lennon 1999), and alpine flora in Switzerland (Grabherr et al. 1994). Shifts in entire species' ranges towards the poles and up mountainsides have been found for butterflies in both North America and Europe (Descimon 1995, Parmesan 1996, Parmesan et al. 1999).

These relatively straightforward patterns of change were predicted by global warming scenarios prior to these observations (multiple authors in Peters and Lovejoy 1992 and in Kareiva et al. 1993). Remarkably, these climate-impact patterns have emerged despite a plethora of independent confounding factors which also impact the quality and spatial distribution of habitats. The consistency among these disparate studies, their correlations with climate data, and a myriad of background experimental work, strongly support the hypothesis that these shifts of species boundaries are, indeed, causally related to recent climatic trends (Christiansen 1999, Easterling et al. 2000a, Hughes 2000, Parmesan et al. 2000, Walther et al. 2002, Parmesan and Yohe 2003, Parmesan in press, Parmesan and Galbraith 2004, multiple authors in Lovejoy and Hannah in press).

\section{Limitations of temporal studies}

As illuminating as long term studies have been, there are three main limitations of temporal datasets (discussed in more detail in Parmesan 2002):

1) few time series of biological data are available for periods longer than the last 30 years;

2) it is often not practical or possible to gather temporal data with good replication over a wide spatial scale. Thus, many of these studies cannot resolve whether range-related changes in populations (e.g. southern species increasing in abundance) represent actual shifts in species range, or just changes in abundance within a fixed range;

3) if no change occurs, interpretation is nearly impossible.

This last problem is particularly relevant to climate change studies. By including stable as well as changing species from multi-species studies, Parmesan and Yohe (2003) estimated that $50 \%$ of wild species have responded to regional warming trends over the past century. But, out of the 920 species with long term data, more than a third $(37 \%)$ have shown no statistically significant change in abundance or distribution, in spite of regional climate change (Table 1). Such patterns are also common in paleontological studies. Authors often provide plausible explanations for the relative stability of some species as compared to others during times of climate change, but these are rarely tested against alternate hypotheses (Parmesan 2002).

As an illustration, consider alternative explanations for a classic paleontological pattern. Studies of species' 
Table 1. Summary of recent major studies of distributional changes for 920 wild species. With the exception of a few $(<6)$ species with data from very large geographic regions (continental), studies were all multi-species and long term ( $>20$ years). The 'predicted' direction is a change predicted by global warming scenarios (Peters 1992, Schneider 1993). Predicted responses to climate warming include poleward and upward range shifts and, for locations which contain ecotones involving species having fundamentally different geographic ranges (i.e. higher vs lower latitudes, or upper vs lower altitudes) southerly species should outperform northerly species at the same site. For $24 \%$ of species, there was no clear prediction, either because the species were cosmopolitan or because observed change was orthogonal to global warming predictions (e.g. general range expansion). Summarized from Table $1 \mathrm{~b}$ of Parmesan and Yohe (2003).

\begin{tabular}{|c|c|c|c|c|}
\hline Type of change & Taxa studied & $\begin{array}{l}\text { Changed in } \\
\text { direction } \\
\text { predicted }\end{array}$ & $\begin{array}{l}\text { Changed opposite } \\
\text { to prediction }\end{array}$ & Stable \\
\hline \multicolumn{5}{|l|}{$\begin{array}{l}\text { Distributional changes (expansions } \\
\text { and contractions along range edges) }\end{array}$} \\
\hline $\begin{array}{l}\text { At poleward range edges (high } \\
\text { elevation) }\end{array}$ & $\begin{array}{l}\text { Tree, herbs, mammals, birds, } \\
\text { butterflies }\end{array}$ & $57 \%$ & $13 \%$ & $30 \%$ \\
\hline $\begin{array}{l}\text { At equatorial range edges (low } \\
\text { elevation) }\end{array}$ & Birds, butterflies & $28 \%$ & $19 \%$ & $52 \%$ \\
\hline $\begin{array}{l}\text { Community changes (local abundance } \\
\text { changes) }\end{array}$ & $\begin{array}{l}\text { Shrubs, reptiles, amphibians, } \\
\text { fish, marine zooplankton and } \\
\text { invertbrates }\end{array}$ & & & \\
\hline Cold adapted & & $52 \%$ & $7 \%$ & $41 \%$ \\
\hline Warm adapted & & $55 \%$ & $21 \%$ & $24 \%$ \\
\hline
\end{tabular}

movements in response to large climate fluctuations of the Pleistocene glacial cycles repeatedly show that not all species moved in concert (Davis and Shaw 2001). For example, formation of communities with no modern day analog has been documented for trees in the midwest United States (Davis and Zabinski 1992) and beetles in the USA and Europe (Ashworth 1997, Morgan 1997, Ponel 1997). These discontinuities have either been attributed to varying lag times of response (associated with differential reproductive rates and dispersal abilities), or to non-analog climate conditions (Graham and Grimm 1990, Huntley 1991, Webb and Bartlein 1992). However, alternate scenarios are equally plausible.

For instance, some species' may have had wider fundamental climatic tolerances than evident from their observed distributions (as in the Drosophila example above). Consider a population at the southern edge of the range during the beginning of an interglacial (warming) period. It is possible that those individuals could physiologically tolerate warmer conditions, but the extension of their range southward are limited by biotic interactions, such as competition (Connell 1961, Davis et al. 1998) and predation (Hochberg and Ives 1999), or by a specialized soil requirement. Under such conditions, we would not necessarily expect this population to respond to a warming trend by going extinct or by moving northward. Such a population could remain stable during the climate change, while others species were undergoing distributional change, thus forming novel local communities.

Consider another example, again studying responses to past climate change. Small mammals exhibited relatively slight range shifts during early Holocene climate change compared to insects and plants. This might give the impression that these animals are little affected by climatic regime. Quite the contrary is evident.
It has been shown that temperature changes have profound effects, but that small mammals may compensate by alterations in body size rather than shifts in range (Hadly 1997, Smith and Betancourt 1998, Smith et al. 1998). In fact, fluctuations of body size in woodrats are so precise that Smith and Betancourt (1998) have referred to them as "paleothermometers."

In general, these types of temporal observations work well to support hypotheses when the predicted response occurs, but are difficult to interpret if no change is found. With respect to climate change scenarios, a finding of no response cannot be used to tease apart a suite of interactions operating at the range edge. At least three processes must be considered as potential explanations of such a finding: climatic sensitivity of the organism with ecological response but long lag time (slow response), climatic sensitivity with evolutionary response (local adaptation), or climatic insensitivity. Any combination of these three phenomena could result in relative stability of the distribution during current climate warming.

\section{Experimentation}

Even with time-series data, there remains the problem that correlations may exist among extrinsic variables which would result in suites of variables changing through time in concert. When one factor has been of particular interest, researchers have turned to controlled manipulations in laboratory or garden settings to isolate this variable and test for response. These single factor, small scale processes have then been extrapolated to explain geographic patterns. An extension of these very controlled manipulations is the transplant experiment. Populations are placed outside the normal range of the 
species, with the transplant spot chosen to be similar/ different in specific characteristics such that the environment is changed in a limited, known way from the native environment. Thus, to look at the effect of temperature averages on controlling the northern border, one might select a site for transplant $100 \mathrm{~km}$ north of the range edge but 'control' for other variables by choosing the site to be similar in elevation, topography, soil, and general biotic community to that found at natural populations within the species' range.

An excellent example of this approach was used to implicate climate change driving a northward range shift of the sachem skipper butterfly (Atalopedes campestris) from California to Washington. Laboratory experiments on temperature tolerance showed that this species is easily killed by a single, short exposure to extreme low temperatures $\left(-10^{\circ} \mathrm{C}\right)$, or repeated exposures to $-4^{\circ} \mathrm{C}$. Transplants north of the existing range edge implicated winter mortality as a primary constraint on population viability. Further, actual northerly range expansion has followed the January average minimum $4^{\circ} \mathrm{C}$ isotherm as it shifted northward from 1950 to 1998 (Crozier 2003, 2004).

\section{Pseudo-experiments: invasions}

Invasions, planned or otherwise, can be viewed as a transplant experiment, and are a reasonable way to 'test' theories of range limitations. From what work has been done, the general wisdom is that climate is a key feature determining success of an invasion (Elton 1958, Moyle and Light 1996, Simberloff and Stiling 1996). But evidence also suggests that climate analyses alone do not always accurately predict the ultimate range of an invader: other factors, such as soil types and dispersal ability, clearly play important roles (Mack 1996). For example, Ehrlich (1989) found that range size of sparrows and rats in invaded regions was much smaller than it would have been because of climate alone, implying that some other factors, such as competitive interactions, restrict range and size. Similarly, Sax (1999) and Sax et al. (2002) found that exotic species tend to invade islands at lower latitudes than they invade continents. This result is consistent with theories which suggest that low latitude boundaries are limited by biotic interactions (Dobzhansky 1950, MacArthur 1972, Kaufman 1998). That is, one possible explanation of the observed pattern is that the depauperate nature of islands results in less biotic pressures on invaders (MacArthur and Wilson 1967, Brown and Lomolino 1998) and, hence, allows a species to persist at lower latitudes than when competitors are present.

\section{True experimental approaches}

Small scale experimental approaches have helped us to understand causative factors producing range edges in a few specific systems. A majority of the experimental work, and nearly all of the laboratory work has dealt with physiological questions. Muth (1980) used laboratory studies on desert iguana egg tolerances and field observation of successful egg burrows to show that location of egg burrows is limited by soil temperature and water potential. He then suggested that these findings may explain the geographic range of the desert iguana in western North America. Salt (1952) and Hayworth and Weathers (1984) demonstrated a close association between metabolic efficiency at varying temperatures and vapor pressures to the distribution of finches and magpies.

Field manipulations have allowed the teasing apart of the relative importance of environmental factors (e.g. temperature) and of biotic interactions (e.g. competition). Connell's (1961) classic experimental study in the rocky intertidal showed that the upper limit of a barnacle's distribution was set primarily by abiotic factors related to heat and desiccation stress, while the lower limit was set by biotic factors, especially interspecific competition with other barnacles. Transplant experiments with intertidal mussels have resulted in the same conclusions (Iwasaki 1995).

Four species of chipmunks in the Rocky Mountains were determined to be parapatrically distributed along an elevational cline (Heller 1971, Heller and Gates 1971). Based on both laboratory experiments and field observations, two of the species were shown to exhibit relatively narrow environmental tolerance but high competitive ability, whereas the other two species exhibited greater environmental tolerance but poor competitive ability. Heller showed that the environmentally sensitive species were limited by abiotic factors, whereas the competitively weak ones were limited by biotic interactions.

\section{Hypothesis testing through scaling-up experimental results}

Can understanding mechanisms of species distributions at the local scale elucidate mechanisms operating across a species' range? Using the same two barnacle species as Connell (1961) and Paine (1977), Wethey (1983) found that the competitively superior Semibalanus balanoides was less tolerant to heat, desiccation and exposure than Chthamalus fragilis and thus always occupied lower areas of the intertidal. In areas of shade or northern exposure, however, Semibalanus was able to occupy a much wider intertidal zone, at the expense of Chthamalus, which was smothered or plowed off the rocks. This mechanism appears to also explain the 
northern range limit of Chthamalus. North of its current range, Chthamalus has demonstrated an ability to settle and survive, but is excluded from developing viable populations by Semibalanus, which, thanks to colder water temperatures, is able to establish unusually high in the intertidal.

Inferring processes at the scale of geographic ranges from results of such small scale experimental studies will not always be accurate. Many factors play a role in setting distributions at the geographic scale that may not be important at the local scales of experimental settings. These may include landscape topography, patterns of wind or ocean currents, and complex, community-level biotic interactions. Nevertheless, manipulation over a whole species range is impractical, so these extrapolations will continue to provide crucial insight.

\section{Linking biogeographic patterns to population processes}

\section{Attempt at a general approach}

Caughley et al. (1988) developed an approach to understanding the determinants of species' boundaries which they applied to a kangaroo data set, but suggested may be generalizable to other taxa. Their method began with documenting the rates of change of individual and population-level fitness characteristics across the species' range. They then proposed that different relative patterns of change among the variables formed templates, with each template linked to a different class of causal factor limiting the species' range. One template suggested fixed resource-delineated boundaries, another suggested subtrate-delineated boundaries, another suggested climatic limitations, etc.

The specific species' characteristics which they measured for kangaroos were animal density in core vs range edge, and individual 'well being' (stored fat, weight, etc.). In kangaroos, these traits appear to respond differently to biotic and environmental gradients across the range, and so comparisons of their patterns of change from core to periphery were used to provide insight into factors which limit the range boundaries for the different kangaroos in Australia.

One drawback to this method as a general approach is that, for most taxa, both abundance and well being can respond in a similar way to a whole suite of environmental conditions. For example, fluctuating asymmetry (FA) is often used as a measurement of perceived environmental stress. FA can increase in response to either abiotic or biotic stresses (Parsons 1990). Moreover, Caughley et al.'s approach relies heavily on abundance as an estimate of how individuals and populations are responding to environmental conditions across sites. However, abundance, by itself, might be a misleading estimate of how good or bad a site is perceived by organisms. For example, if populations with high abundance are entirely composed of juveniles that never reach adulthood, and thus rely on immigration to persist, then an estimate of abundance might obscure the fact that the environmental conditions at that site are not adequate for an independent population to persist through time.

A more direct approach is to study the geographic variation of individual traits that are known to respond to specific environmental stresses. For example, among marine invertebrates, insects, plants, and vertebrates the concentration and induction temperature of heat shock proteins responds in a characteristic way to environmental temperature (Hofmann 1999, Feder 1999). An assessment of geographic variation in the proportion of heat shock proteins found within individuals can provide information on the relative importance of temperature as a limiting factor of species' ranges.

\section{Case study of climate change: Edith's checkerspot butterfly}

Knowledge at many different levels can be integrated to address complex questions, such as to what extent wildlife has been affected by 20th century climate change. Lepidoptera have been particularly well studied with respect to climate influences (reviewed by Parmesan 2003). One species of lepidoptera, Edith's checkerspot butterfly (Euphydryas editha), has a 40-year history of basic research by more than a dozen researchers from which we can draw a population-based, mechanistic understanding of continental wide distributional changes.

In western North America, E. editha has shifted northward and upward over this century (Parmesan 1996). The magnitude of shift in mean location of populations of $92 \mathrm{~km}$ north and $124 \mathrm{~m}$ upward matched the observed warming trend over the same time period and region: mean yearly temperature isotherms shifted $105 \mathrm{~km}$ northward and $105 \mathrm{~m}$ upward (Karl et al. 1996). Further, the cline in frequency of population extinctions had a breakpoint at $2400 \mathrm{~m}$ (fewer extinctions at the highest elevations). This breakpoint correlated to that for trends in snowpack depth and timing of snowmelt over the past 50-100 years (decreased depth and earlier melt-date below $2400 \mathrm{~m}$, Johnson et al. 1999). Direct habitat degradation was controlled for, and patterns of surrounding habitat destruction did not correlate with the natural extinction patterns (C. Parmesan, unpubl.). At the large scale, these correlations make climatic warming the most likely candidate for assigning causation to the range shift.

Forty years of empirical studies on E. editha at the population level point to likely mechanisms driving the 
differential extinction patterns. Many population extinctions have been associated with particular severe climatic events (e.g. drought and frost; Singer and Ehrlich 1979, Ehrlich et al. 1980, Singer and Thomas 1996). An increase in such extreme climatic events has been predicted from anthropogenic global warming, and significant trends in this direction have been found for the U.S.A. (Easterling et al. 2000a, b, Meehl et al. 2000a, b). Further, observational and experimental studies have shown that temperature drives population dynamics, extinctions and colonizations by shifting the relative phenologies between larval development and host-plant senescence (Singer 1972, Weiss et al. 1988, Boughton 1999).

The observed northward and upward range shift of E. editha during this century has occurred as a result of increased numbers of population extinctions at the southern range boundary and at lower elevations, with a symmetrical tendency towards population stability at northern and upper boundaries. Thus, increases in infrequent, severe, climate events appear to be driving a northward and upward range shift in this species, via impacts on population extinction and colonization dynamics, which in turn are driven by phenological synchrony of the host plant (Parmesan 1996, 2003, Parmesan et al. 2000).

\section{Underexploited arenas: physiological plasticity and insect diapause}

There are many other cases where much biological detail is known about species or taxa that could be used to formulate and test hypotheses of range limits. For example, the physiology of insect diapause has been intensively studied. Diapause in insects is characterized by the reduction or elimination of growth, development and/or reproduction at specific developmental stages, and involves a complex suite of hormonal, physiological and behavioural changes (Tauber et al. 1986). Diapause is a major means by which insects adapt to seasonal variation in their environments: the majority of insect species outside the tropics exhibit diapause under at least some conditions (Danks 1987). In tropical species, diapause is usually restricted to those living in seasonal environments (Denlinger 1986). Tropical insects lacking diapause typically have multiple, overlapping generations.

Diapause in a species may be either obligatory (occurring each year regardless of environmental conditions) or facultative (induced by seasonal environmental cues). In herbivorous insects, obligatory diapause occurs most frequently in species at higher latitudes and elevations (where growing seasons are short) and in species whose life cycle is strongly dependent on hostplant phenology. In contrast, many species with faculta- tive diapause exhibit within-species variation in the number of generations per year (voltinism). In the northern hemisphere, southern populations tend to have multiple generations per year while northern populations tend to have only one generation.

These differing patterns of diapause suggest some interesting contrasts about the predicted effects of climate and climate change on the northern species borders of herbivorous insects. First, outside the tropics, generalist species lacking diapause are more likely to be limited by minimum winter temperatures than by average annual or seasonal conditions at their northern species border. Indeed, because non-diapause species generally lack freeze tolerance, we might expect the northern borders of such species to cluster near areas where minimum winter temperatures fall below tissue freeze point $\left(\sim-4^{\circ} \mathrm{C}\right)$, as was seen in the Sachem skipper butterfly. This is of interest because anthropogenic climate change has been predicted to increase minimum (nighttime) temperatures more than maximum (daytime) or average temperatures, and to exhibit stronger change at higher latitude. Both of these trends have now been documented in global temperature data for the 20th century (Easterling et al. 1997, IPCC 2001b).

Second, diapausing species that are univoltine at their northern border are more likely to be limited by the length of the growing season (e.g. by accumulated degree-days above some minimum growth threshold) than by minimum winter temperatures. Third, facultative diapausers that are multivoltine at their northern border are likely to be directly limited by factors other than climate (though of course these other factors may correlated with climate). Finally, specialist herbivores with obligate diapause will be particularly sensitive to changes in the phenology of their host plants that may result from climate change (Harrington et al. 1999), as seen in Edith's checkerspot example above.

However, evolutionary and ecological factors other than climate can also impact diapause strategies, and hence range boundaries. For instance, rapid evolutionary shifts in some aspects of diapause can facilitate rapid shifts in species borders of colonizing species, a phenomenon best illustrated by agricultural pests. For example, apple maggots (Cydia pomonella) and pink bollworms (Pectinophora gossypiella) have both invaded North America and/or South America during the past two centuries, and rapidly spread over wide geographic ranges. Current-day populations exhibit heritable differences in critical photoperiod that have evolved during, and allowed, this expansion.

Other aspects of diapause response are much less evolutionarily labile. For example, many tropical species that historically exhibited diapause have expanded their ranges into temperate regions during the past several centuries. This expansion was likely facilitated by 
evolutionary changes in the environmental determinants of diapause. However, there are no cases that document the de novo evolution of diapause in temperate insects from completely non-diapausing tropical species (Tauber et al. 1986). Thus, as with all other types of analyses on species' distributions, predictions from physiological studies concerning responses to environmental change hinge on knowing how evolutionarily labile the traits of interest are, and whether climate, predation, or competition drives these variations in the traits at the range edge.

\section{Cross-system contrasts}

We have argued that static correlations between environmental variables and species' boundaries are necessary but are often insufficient to determine the limiting factors in species distributions. Uncertain knowledge of the mechanistic basis of species' range limits weakens conclusions from biogeographic studies. Focusing on climate change impacts, Parmesan and Yohe (2003) modeled the theoretical impact of this uncertainty on the strength of conclusions that could be drawn from observed changes in species' distributions. Even though $81 \%$ of distributional changes are in the direction predicted by regional warming, and the statistical probability of this trend being random is less than one in a billion, the correlational nature of this data leaves room for uncertainty. If we add temporal responses and a high level of detailed population ecological and physiological knowledge, the model shows that confidence levels for assigning causation go up, implying that predictions of future responses are likely to be more accurate.

Thus, the conclusion that climate change is indeed driving species range shifts relies on substantial supporting empirical research. But reproductive behaviors, micro habitat requirements, and histories of local populations and habitat changes are rarely well documented for any given species, and we know even less about how those parameters differ for populations on the range edge. We suggest that comparisons across systems - that is, across species, across scales, taxonomic groups or biomes, or across marine vs terrestrial systems - is a relatively untapped source for hypothesis building and testing which requires little additional detailed research.

\section{The need for new approaches}

There is a dearth of conclusive empirical support for hypothesized causal factors operating at species boundaries, indicating a need for new approaches to understanding species range limits. An exhaustive search of BIOSIS and Current Contents databases within the period of 1985 to 1999 yielded a total of 145 publications aimed at understanding causal determinants of species' borders (Table 2). The first striking result is the low total numbers of studies. By comparison, a search in BIOSIS on the subject of population dynamics during the same period produced 17095 publications.

Taxa and geographic location of the 145 studies of species' borders are highly skewed. The majority of the studies (110) were done on terrestrial systems, while 34 dealt with marine organisms. Moreover, most (79) of the terrestrial studies were conducted in northern temperate systems, with the remainder largely conducted in tropical regions of the southern hemisphere. Surprisingly, average scale was quite large, with studies typically analyzing distributional data spread over regional or continental scales (98). However, records were often coarse resolution, with only 46 publications exploring distributions along local elevational or environmental gradients.

The literature was characterized in three ways (Table 2):

1) approach used: studies were classified as using a biogeographic (Grinnellian-type) approach, a population based approach, or a combined mixture of approaches. Population based studies were further classified as demographic (birth rate, mortality, immigration, or emigration data), temporal (abundance and distribution data compiled over multiple time periods) or experimental (manipulation of factors or individuals). The experimental studies were further sub-divided into physiological or ecological;

2) extent and depth: studies which analyzed the entire range edge were divided from those which analyzed only a portion, as were those which compared multiple species, or multiple causal mechanisms;

3) supportability: indicates studies in which the predicted range-limiting mechanisms were supported by independent empirical data.

It is evident that the biogeographic approach outlined by Grinnell nearly a century ago is still widely used by researchers. More than half of the studies $(54 \%)$ associated abundance, distribution, or physiological tolerance levels to a known environmental gradient. More detailed studies are not uncommon, however, with demographic, experimental, or temporal approaches used in 59\% of studies. Finally, there were relatively few $(16 \%)$ studies which combined different approaches.

Population based studies and those which combined multiple approaches appeared better able to provide support for predicted mechanisms: $68 \%$ of population based and $71 \%$ of combined approaches resulted in empirical support of the stated hypotheses. In contrast, only $16 \%$ of Grinnellian-type studies provided such support (beyond static correlational associations). 
Table 2. Literature review of publications on empirical studies of the determinants of species' borders. Each paper was classified according to the approach used. Each paper was further classified as providing/not providing sufficient evidence to support the predicted range limit(s). A paper may appear in more than one 'approach' category. A full list of references used in the construction of this table is in an appendix available at http://www.oikos.ekol.lu.se

\begin{tabular}{lccccc}
\hline Approach & $\begin{array}{c}\text { Total } \\
(\mathrm{n})\end{array}$ & $\begin{array}{c}\text { All edges } \\
\text { considered } \mathrm{n}(\%)\end{array}$ & $\begin{array}{c}\text { Multiple species } \\
\text { studied } \mathrm{n}(\%)\end{array}$ & $\begin{array}{c}\text { Multiple mechanisms } \\
\text { studied n (\%) }\end{array}$ & $\begin{array}{c}\text { Predicted mechanisms } \\
\text { supported } \mathrm{n}(\%)\end{array}$ \\
\hline All studies & 145 & $41(28)$ & $103(71)$ & $74(51)$ & $48(33)$ \\
Biogeographic & 79 & $22(26)$ & $54(68)$ & $45(57)$ & $13(16)$ \\
Population-based & 85 & $24(28)$ & $60(71)$ & $40(47)$ & $58(68)$ \\
$\quad$ demographic & 7 & $1(14)$ & $3(43)$ & $5(71)$ & $6(86)$ \\
Experimental (field +lab) & 26 & $1(4)$ & $14(54)$ & $12(46)$ & $72(85)$ \\
$\quad$ ecological & 32 & $18(56)$ & $23(72)$ & $11(22)$ & $7(22)$ \\
$\quad$ physiological & 20 & $5(25)$ & $14(70)$ & $13(62)$ & $15(75)$ \\
Temporal & 23 & $4(19)$ & $13(62)$ & $15(71)$ \\
Combined & & & & \\
\hline
\end{tabular}

Counter to expectation that population based studies may suffer reduced generality, we found that the proportion of population based studies which considered most of the range edge was similar to biogeographic approaches ( $28 \%$ and $26 \%$, respectively).

To achieve both generality as well as solid mechanistic underpinnings, it is evident that either more studies need to combine population-level and geographic approaches (often a practical difficulty) or some new approaches need to be developed. Comparisons across distinct systems may be one such approach where little detailed knowledge would be required yet falsifiable hypotheses could be rigorously tested.

\section{Multiple species as replicates (hypothesis testing within systems)}

The simplest kind of cross-system contrast is a comparison of related species. Species within a taxon serve as replicates for hypotheses on distribution limits of a given kind of organism. Studies of this kind have used the excellent distributional data available for many birds, mammals, beetles, butterflies and trees to suggest or support general theories of distributional limits.

For example, E. editha may represent a 'typical' butterfly, as population level studies of many species of butterflies have shown that this taxa is particularly sensitive to climatic parameters, responding strongly to both micro climate and to yearly climatic variations (reviewed by Ford 1945, Dennis 1993, Parmesan 2003). Such studies led to a generally accepted belief that butterfly distributions are limited primarily by temperature requirements. Recent climate change allowed this hypothesis to be 'tested' on a large scale across multiple species. Parmesan et al. (1999) documented significant effects of regional temperature increase on the range limits of 57 species of temperate, non-migratory butterflies in Europe. Two-thirds of the species re- sponded to the $0.8^{\circ} \mathrm{C}$ warming trend over the 20th century by shifting their ranges northward. Changes in range limits occurred at both the southern and northern range edges, with southern boundaries contracting by as much as $50 \mathrm{~km}$, and northern boundaries expanding by as much as $200 \mathrm{~km}$.

As well as providing this single overall support for previous theories of range limits, sufficient replication allows the variance within a taxon to be studied in its own right. With respect to climate change alone, replication allows us to ask: are all species moving at the same rate? Do different species appear to be responding to individualistic sets of climate variables? Species can be classified as 'responsive' (shifting range) or 'non-responsive' (stable) with respect to climatic change (Table 1). What, then, are the characteristics associated with being responsive or non-responsive to climate change? What is the role of phylogeny in shaping species' responses?

MacArthur (1972) expanded the ideas developed in the experiments of intertidal ecologists to terrestrial biogeography suggesting that high latitude range limits of birds may be set by abiotic factors related to cold temperatures while southern limits may be set by interspecific competition among the densely packed species in the tropics. Kaufmann (1998) used distributional data of new world mammals to test this idea. Kaufmann predicted that, because abiotic factors tend to be correlated with latitude, abiotically produced range edges would tend to be geometrically regular and correspond to latitudinal isotherms (e.g. temperature) while biotically limited range edges would tend to be irregular and have little association with any underlying environmental surface. Using a geometrical analysis of spatial data, she found that high latitude range edges were less convoluted than low latitude edges in the temperate zone. However, there was no difference between northern and southern edges within the tropics (Kaufman 1998). Both of these results lend support to MacArthur's hypothesis. 


\section{Cross-system contrasts (hypothesis testing across systems)}

\section{The logic of cross-system contrasts}

The logic underlying this idea of cross-system contrasts has three components. First, one proposes a hypothesis that the borders for a species or related systems are determined by some key limiting biological property interacting with some limiting environmental factor. Second, this hypothesis predicts that contrasting species or systems that differ in these key biological properties should differ in their responses to different environmental factors. Third, we can test these predictions by examining how geographic patterns of species borders in these contrasting systems relate to changes or gradients in environmental factors. These predictions can be evaluated using both temporal and spatial patterns.

Below we present one example that illustrate how contrasts across systems may be developed and applied. The basic first step is to identify the key biological property of interest for a pair of species or systems and then describe how this generates predictions about different environmental factors that limits borders in each group in time or space. Our comparison uses two very different systems - marine mollusks vs terrestrial plants and animals - to test a prediction generated with this approach.

\section{A cross-system approach: contrasting geographic zones - the Earth, the oceans and Rapoport's rule}

One of the most powerful tools in the arsenal of crosssystem comparisons may come from differences in the physical environment among terrestrial, marine and freshwater habitats. Over the last few decades, numerous studies have noted geographical patterns in species distributions, including several related to latitude (overview by Brown and Lomolino 1998). For example, some taxonomic groups show a latitudinal trend in average range size (measured as the maximum latitudinal extent of the geographical range), with larger average range sizes occurring at higher latitudes (Rapoport 1982, Stevens 1989, but see Gaston 1996, Gaston et al. 1998). This pattern has been christened Rapoport's rule in recognition of its original discovery by Eduardo Rapoport (1982) and has attracted considerable attention because of its potential implications for latitudinal patterns of species diversity (Stevens 1989, Colwell and Hurtt 1994, Taylor and Gaines 1999). As with most large scale patterns in ecology, however, rigorously testing hypothesized mechanisms to explain the patterns is a daunting challenge.

Like many issues related to geographical ranges, Rapoport's rule is essentially a pattern stemming from the location of species borders. Hypotheses to account for the pattern must therefore be based on knowledge or speculation about the factors determining where species borders occur. In the case of Rapoport's rule, several hypotheses have been proposed (Stevens 1989, Colwell and Hurtt 1994, Sax 1999). One prominent explanation proposed by Stevens (1989) is based on seasonality in the physical environment. The logic is as follows:

\begin{abstract}
"The seasonal variation within [a] location sets the minimum breadth of tolerances required by individuals that. ... reside in each site. A non-migratory individual ... must be able to tolerate the full range of climatic conditions imposed on it by seasonal change. Individuals of such a broadly tolerant species can reside in more sites, hence the geographical ranges of high latitude species are larger than those [of] species of low latitudes."
\end{abstract}

(Stevens 1996)

An alternative hypothesis posits that Rapoport's rule may at times be a simple byproduct of geometric constraints imposed by geographic boundaries (e.g. the edge of continents - Colwell and Hurtt 1994). Species with large geographic ranges are likely to hit the edge of a continent before their habitat ends. Therefore, average range sizes necessarily decline as geographic boundaries come closer together, such as the east and west coasts of the U.S.A. compared to the east and west coasts of the isthmus of Panama. Depending upon the distribution of actual range sizes, this geographic constraint can generate patterns consistent with or opposing Rapoport's rule (overview by Colwell and Lees 2000).

Distinguishing between these and other hypothetical causes of latitudinal trends in range size is difficult, because the purported mechanisms are rarely amenable to experimental tests. Cross system comparisons that are based on habitat differences in climate or geometry, however, may prove quite powerful. Consider the seasonality hypothesis. This hypothesis rests on two important assumptions. The first assumption is implicit - species borders are set primarily by climatic tolerances. If tolerances to climatic conditions are not the primary cause of species borders, there should be no logical connection between individual tolerances to seasonal variation and geographical ranges.

The second assumption of the seasonality hypothesis is generally stated explicitly - high latitude environments are more seasonal than low latitude environments. Although this pattern is widely viewed as correct, its basis in fact depends on the habitat of interest and the relevant physical parameters. Our perception of seasonality increasing with latitude comes from our terrestrial perception of the globe and relates primarily to patterns of terrestrial temperature and light. In other systems, such as the ocean, seasonality can show a very different latitudinal trend. 
(a) Terrestrial
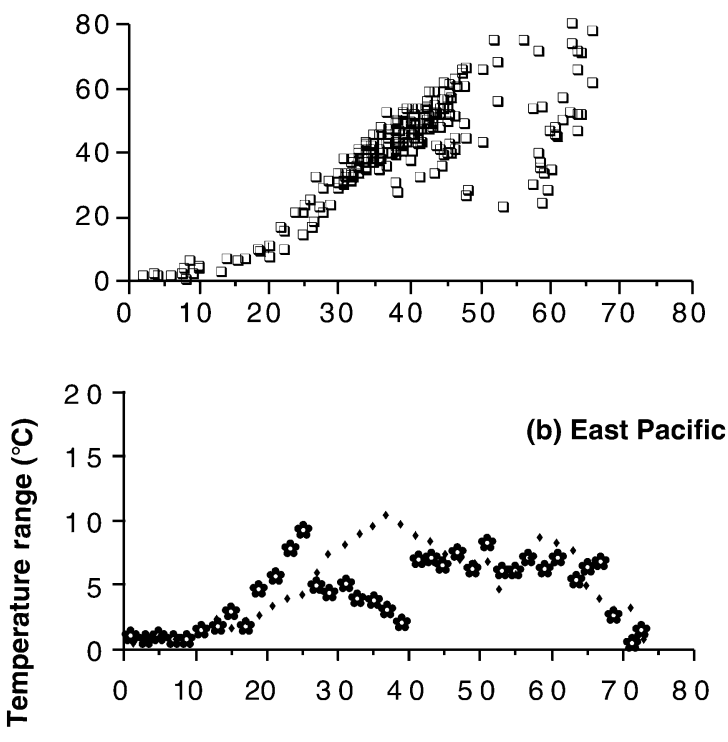

\$ coast $\quad$ mid ocean

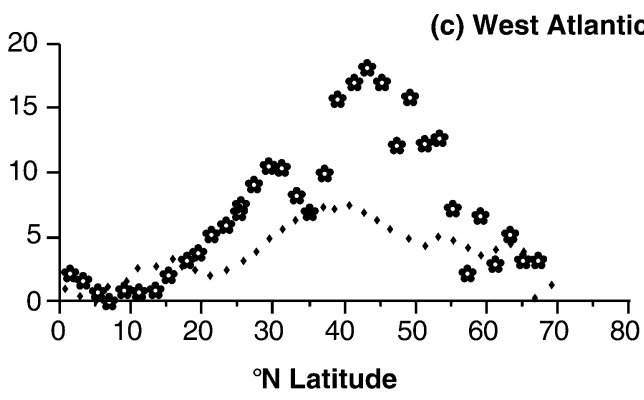

Fig. 1. Seasonal variation in temperature for three habitats: (a) terrestrial, (b) marine, east Pacific, and (c) marine, west Atlantic. In each case, data are the difference between the average temperature of the coldest and warmest month. Terrestrial temperature data are based on 312 sites from North and South America, from Kaufman (1998). Ocean temperature data are from monthly composites compiled by the National Oceanographic and Atmospheric Administration from ten year averages.

For example, Fig. 1 shows the latitudinal patterns of temperature variation for ocean and terrestrial habitats in North and South America and their adjoining oceans. Each figure plots the seasonal range in average monthly temperatures. On land, seasonal variation in temperature generally increases with increasing latitude. By contrast, in both the eastern Pacific and western Atlantic, seasonal variation in temperature peaks at middle, temperate latitudes. The decline in seasonal variation towards the poles reflects differences in the physical characteristics of air and water. The higher heat capacity of water relative to air, the constraints on water temperatures dropping much below $0^{\circ} \mathrm{C}$, and the insulating effects of surface ice all lead to relatively low seasonal variation in water temperatures at high latitudes. Presumably measurements from the deep sea would show yet a third pattern with little seasonality in temperature at any latitude.

These different patterns of seasonality in temperature offer the possibility of much more compelling tests of the seasonality hypothesis. If seasonality in the physical environment is indeed the primary cause of Rapoport's Rule, the exceptions to the rule should be predictable. Habitats with different latitudinal patterns of seasonality should have predictably different patterns of latitudinal variation in range size. Intriguingly, one of the bestdocumented exceptions to the pattern of reduced range size at low latitudes comes from marine species; molluscs (Roy et al. 1994, 1998). Analyses of more than 2800 species ranges show no monotonic decline in range size from polar to tropical latitudes in clear violation of Rapoport's rule. Since seasonality does not decline monotonically towards the tropics in the ocean, however, this "exception" could prove the rule. If seasonality is indeed the underlying cause of latitudinal variation in range size, the pattern for marine taxa should show a peak in range size at middle latitudes.

To examine this prediction, we have plotted the range size data from Roy et al. 1998 as a function of the seasonal variation in mean monthly temperatures from Fig. 1. If increased seasonality drives increases in latitudinal range, we would expect a positive correlation between these two metrics. Figure 2 plots these data for both the eastern Pacific and western Atlantic coasts of North and Central America. Contrary to the prediction, there is no relationship between seasonal variation in temperature at a given latitude and the median range of

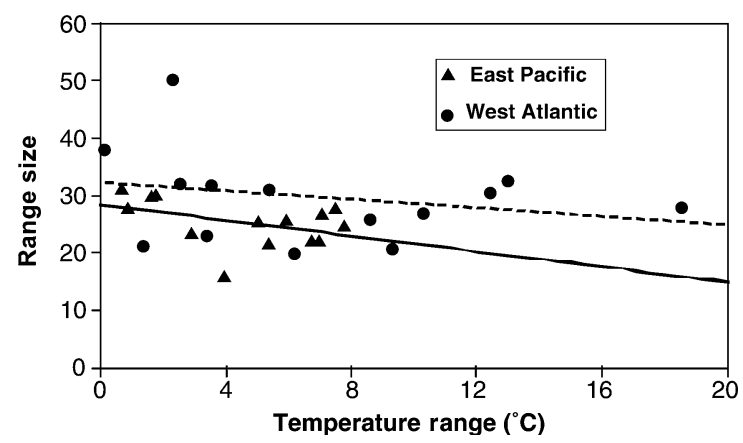

Fig. 2. Correlation between seasonal variation in temperature [(maximum monthly mean) - (minimum monthly mean)] and median latitudinal range size for marine molluscs (from Roy et al. 1998) in the east Pacific (triangles) and west Atlantic (circles). Data are binned in $5^{\circ}$ latitudinal groups. Temperature variation explains 5\% (west Atlantic) and 16\% (east Pacific) of the variation in median range size. 
species that live there. Molluscs not only present an exception to Rapoport's rule, but also raise doubts about the validity of the connection between range size and seasonality of climate.

\section{Future prospects}

This approach can be extended to a host of other possible contrasts: such as, endothermy vs ecothermy, annual vs perennials, sexual vs asexual, sedentary vs migratory, flying vs earthbound, varying numbers of generations per year, small vs large range size, active vs passive dispersal, varying trophic levels or habitat specialists vs generalists.

One factor which has emerged as particularly influential in theories of dynamics at boundaries is the Allee effect (Holt and Gaines 1992, Keitt et al. 2001). This effect encompasses a suite of traits which affect reproductive success, based on the effects of spacing, density and timing on successful meeting of gametes. Thus, pollinator densities and dispersal abilities are important for reproduction in many flowering plants (Groom 1998, Lind 1994) and high conspecific density is crucial to breeding in captive mongoose lemurs (Hearn et al. 1996). There is also evidence that Allee effects may increase extinction probabilities of small populations (Kuussaari et al. 1998) and may be responsible for the failure of many bio-control programs (Hopper and Roush 1993). But organisms with high mobility are less subject to this effect (Myers et al. 1995, Kindvall et al. 1998). Species that differ in their sensitivity to Allee effects are likely to differ in the factors that limit their range boundaries, and in their responses to environmental change at those boundaries as well.

Success of the cross-system approach lies in defining the appropriate level of taxonomic and geographic aggregation for making comparisons and contrasts. Further, there is currently little agreement on the level of biological detail required to make useful predictions about the responses of species borders to rapid environmental change. For instance, the diapause example illustrates that limiting effect of an environmental factor could occur at a critical life history stage (such as diapause), or could be manifested through an organism's entire life history. This level of knowledge is important for determining the appropriate comparisons. Further, systems may or may not currently be in equilibrium with the environmental factors of interest, so something must be known about the dynamics of the systems being studied.

\section{Conclusions}

The science of biogeography has become increasingly sophisticated over recent decades and clearly there is much to be learned from continued empirical studies of biogeographic ranges. Rigorous statistical techniques and sophisticated software programs incorporating artificial intelligence have addressed many of the limitations of correlational data. A move towards more synthetic approaches has led to more robust inferences on the determinants of species boundaries. Decades of research on basic biology now provide a wealth of information that can be combined with continental scale distributional data to understand biogeographic patterns. Data are increasingly being compiled from disparate sources, and movement is towards more centralized archives. Thus, not only are the databases larger, they have become more complete, with better resolution within a taxon and better global coverage across taxa. Complementary to these improvements of the traditional approach, an important new development in biogeography is increasing use of experimentation and the development of mechanistic models.

All of these developments have allowed biogeography to contribute substantially to understanding biotic responses to global change. Particular success has been in the realm of recent climate change. But we are only beginning to tackle the main challenge. Current trends of rapid changes in the underlying environmental surface (climate, uv levels, surface water availability) are expected to continue for the next 100 years. It is essential to address the daunting question of how species' distributions are likely to be impacted by these continued trends.

The improvements in methodologies, databases, and understanding of basic biological processes barely keep pace with ever-demanding needs of the management, conservation and policy communities. As an extreme example of the mismatch between basic and applied sciences, Channel and Lomolino (2000) conclude that knowledge of the basic biology of species' distributions has not been helpful in predicting responses to habitat loss. In a global analysis of 245 species, they demonstrate that species severely impacted by habitat destruction have had any biogeographic "rules" completely overwhelmed by dominate human forces. $\mathrm{Hu}-$ mans appear to have disproportionately destroyed habitat in core areas, making remnant distributions more likely to be composed of former peripheral populations. Therefore, biogeographic theory which postulates that core populations are more stable than peripheral ones did not help to predict the observed response to habitat loss.

However, we argue that future management plans will continue to rely heavily on basic research of species' distributions. These sectors increasingly seek predictive scenarios of biotic response which are both quantitative and of high resolution so that results can be applied at local scales. This need is tempered by the desire of scientists to maintain statistical rigor and falsifiability. 
Such challenging goals present the need for increasingly creative approaches in a field that is largely beyond the realm of traditional experimentation.

Acknowledgements - This paper stems from a workshop held at the National Center for Ecological Analysis and Synthesis. The Institut des Sciences de l'Évolution de Montpellier, University of Montpellier 2 facilitated this work. The authors would like to thank the following for their helpful comments: I. Chuine, M.E. Hochberg, R. Holt, T. Keitt, M.C. Singer, (ISEM publication 2004-039).

\section{References}

Andrewartha, H. G. and Birch, L. C. 1954. The distribution and abundance of animals. - Univ. of Chicago Press.

Antonovics, J. 1976. The nature of limits to natural selection. - Ann. Miss. Bot. Gard. 63: 224-247.

Ashworth, A. C. 1997. The response of beetles to Quaternary climate changes. - In: Huntley, B., Cramer, W., Morgan, A. V. et al. (eds), Past and future rapid environmental changes: the spatial and evolutionary responses of terrestrial Biota. Springer-Verlag, pp. 119-127.

Barry, J. P., Baxter, C. H., Sagarin, R. D. et al. 1995. Climaterelated, long-term faunal changes in a California rocky intertidal community. - Science 267: 672-675.

Beaugrand, G., Reid, P. C., Ibañez, F. et al. 2002. Reorganization of North Atlantic marine copepod biodiversity and climate. - Science 296: 1692-1694.

Beerling, D. J. 1993. The impact of temperature on the northern distribution of the introduced species Fallopia japonica and Impatiens glandulifera in north-west Europe. - J. Biogeogr. 20: $42-53$.

Boughton, D. A. 1999. Empirical evidence for source-sink dynamics in a butterfly: temporal barriers and alternative states. - Ecology 80: 2727-2739.

Brown, J. H. and Lomolino, M. V. 1998. Biogeography, 2nd ed. - Sinauer Associates.

Brown, J. H., Stevens, G. C. and Kaufman, D. M. 1996. The geographic range: size, shape, boundaries and internal structure. - Annu. Rev. Ecol. Syst. 27: 597-623.

Brown, J. S. and Pavlovic, N. B. 1992. Evolution in heterogeneous environments-effects of migration on habitat specialization. - Evol. Ecol. 6: 360-382.

Caughley, G. D., Grice, R., Barker, R. et al. 1988. The edge of the range. - J. Anim. Ecol. 57: 771-785.

Channell, R. and Lomolino, M. V. 2000. Dynamic biogeography and conservation of endangered species. - Nature 403: 26-28.

Christianson, G. E. 1999. Greenhouse: the 200-year story of global warming. - Greystone Books, Vancouver, Canada.

Colwell, R. K. and Hurtt, G. C. 1994. Nonbiological gradients in species richness and a spurious Rapoport effect. - Am. Nat. 144: 570-596.

Colwell, R. K. and Lees, D. C. 2000. The mid-domain effect: geometric constraints on the geography of species richness. - Trends Ecol. Evol. 15: 70-76.

Connell, J. H. 1961. The influence of interspecific competition and other factors on the distribution of the barnacle Chthamalus stellatus. - Ecology 42: 710-723.

Coope, G. R. 1995. Insect faunas in ice age environments: why so little extinction? - In: Lawton, J. H. and May, R. M. (eds), Extinction rates. Oxford Univ. Press, pp. 55-74.

Crozier, L. 2003. Winter warming facilitates range expansion: cold tolerance of the butterfly Atalopedes campestris. - Oecologia 135: 648-656.

Crozier, L. 2004. Winter warming facilitates butterfly range expansion: by increasing survivorship. - Ecology 85: 231241.
Danks, H. V. 1987. Insect dormancy: an ecological perspective. - Biological Survey of Canada, Ottawa, Canada.

Davis, A. J., Jenkinson, L. S., Lawton, J. H. et al. 1998. Making mistakes when predicting shifts in species range in responses to global warming. - Nature 391: 783-786.

Davis, M. B. and Zabinski, C. 1992. Changes in geographical range resulting from greenhouse warming: effects on biodiversity in forests. - In: Peters, T. E. L. and Lovejoy, R. (eds), Global warming and biological diversity. Yale Univ. Press, pp. 297-308.

Davis, M. B. and Shaw, R. G. 2001. Range shifts and adaptive responses to quaternary climate change. - Science 292: $673-$ 679.

Denlinger, D. L. 1986. Dormancy in tropical insects. - Annu. Rev. Entomol. 31: 239-264.

Dennis, R. L. H. 1993. Butterflies and climate change. - Manchester Univ. Press.

Descimon, H. 1995. La conservation des Parnassius en France: aspects zoogéographiques, écologiques, démomographiques et génétiques. - Rapports d'études de l'OPIE. Vol. 1, France.

Dobzhansky, T. 1950. Evolution in the tropics. - Am. Sci. 38: 209-221.

Easterling, D. R., Horton, B., Jones, P. D. et al. 1997. Maximum and minimum temperature trends for the globe. - Science 277: $364-367$

Easterling, D. R., Meehl, G. A., Parmesan, C. et al. 2000a. Climate extremes: observations, modeling, and impacts. - Science 289: 2068-2074.

Easterling, D. R., Evans, J. L., Groisman, P. Y. et al. 2000 b. Observed variability and trends in extreme climate events: a brief review. - Bull. Am. Meteorol. Soc. 81: 417-425.

Ehrlich, P. R. 1989. Attributes of invaders and the invading precesses: vertebrates. - In: Drake, J. A. et al. (eds), Biological invasions: a global perspective (SCOPE). John Wiley and Sons, Ltd.

Ehrlich, P. R., Murphy, D. D., Singer, M. C. et al. 1980. Extinction, reduction, stability and increase: the responses of checkerspot butterfly (Euphydryas editha) populations to the California drought. - Oecologia (Berlin) 46: 101-105.

Elton, C. S. 1958. The ecology of invasions by animals and plants - Methuen and Company.

Feder, M. E. 1999. Organismal, ecological, and evolutionary aspects of heat-shock proteins and the stress response: established conclusions and unresolved issues. - Am. Zool. 39: 857-864.

Ford, E. B. 1945. Butterflies. - Collins, London, UK.

Gaston, K. J. 1996. Species-range-size distributions: patterns, mechanisms and implications. - Trends Ecol. Evol. 11: 197201.

Gaston, K. J. 2000. Global patterns in biodiversity. - Nature 405: $220-227$

Gaston, K. J. et al. 1998. Rapoport's rule: time for an epitaph? - Trends Ecol. Evol. 13: 70-74.

Garcia-Ramos, G. and Kirkpatrick., M. 1997. Genetic models of adaptation and gene flow in peripheral populations. - Evolution 51: 21-28.

Grabherr, G., Gottfried, M. and Pauli, H. 1994. Climate effects on mountain plants. - Nature 369: 448.

Graham, R. W. and Grimm, E. C. 1990. Effects of global climate change on the patterns of terrestrial biological communities. - Trends Ecol. Evol. 5: 289-292.

Grinnell, J. 1917. Field tests of theories concerning distributional control. - Am. Nat. 51: 115-128.

Grinnell, J. 1924. Geography and evolution. - Ecology 5: 225.

Groom, M. J. 1998. Allee effects limit population viability of an annual plant. - Am. Nat. 151: 487-496.

Hadly, E. A. 1997. Evolutionary and ecological response of pocket gophers (Thomomys talpoides) to late-Holocene climatic changes. - Biol. J. Linn. Soc. 60: 277-296.

Harrington, R., Woiwod, I. and Sparks, T. 1999. Climate change and trophic interactions. - Trends Ecol. Evol. 14: $146-150$. 
Hayworth, A. M. and Weathers, W. W. 1984. Temperature regulation and climatic adaptation in black-billed and yellow-billed magpies. - Condor 86: 19-26.

Hearn, G. W., Berghaier, R. W. and George, D. D. 1996. Evidence for social enhancement of reproduction in two Eulemur species. - Zoo Biol. 15: 1-12.

Heller, H. C. 1971. Altitudinal zonation of chipmunks (Eutamias): interspecific aggression. - Ecology 52: 312319.

Heller, H. C. and Gates, D. M. 1971. Altitudinal zonation of chipmunks (Eutamias): energy budgets. - Ecology 52: 424433.

Hill, J. K., Thomas, C. D. and Huntley, B. 2003. Modelling present and potential future ranges of European butterflies using climate response surfaces. - In: Boggs, C. L., Watt, W. B and Ehrlich, P. R. (eds) Evolution and ecology taking flight: butterflies as model systems. Univ. of Chicago Press.

Hochberg, M. E. and Ives, A. R. 1999. Can natural enemies enforce geographical range limits? - Ecography 22: 268276.

Hofmann, G. E. 1999. Ecologically relevant variation in induction and function of heat shock proteins in marine organisms. - Am. Zool. 39: 889-900.

Hoffmann, A. A. and Blows, M. W. 1994. Species borders: ecological and evolutionary perspectives. - Trends Ecol. Evol. 9: 223-227.

Holbrook, S. J., Schmitt, R. J. and Stephens, J. S. Jr. 1997. Changes in an assemblage of temperate reef fishes associated with a climatic shift. - Ecol. Appl. 7: 1299-1310.

Holt, R. D. and Gaines, M. S. 1992. The analysis of adaptation in heterogeneous landscapes: implications for the evolution of fundamental niches. - Evol. Ecol. 6: 433-447.

Houston, A. I. and McNamara, J. M. 1992. Phenotypic plasticity as a state-dependent lifehistory decision. - Evol. Ecol. 6: 243-253.

Hopper, K. R. and Roush, R. T. 1993. Mate finding, dispersal, number released, and the success of biological control introductions. - Ecol. Entomol. 18: 321-331.

Hughes, L. 2000. Biological consequences of global warming: is the signal already apparent? - Trends Ecol. Evol. 15: 56-61.

Huntley, B. 1991. How plants respond to climate change: migration rates, individualism and the consequences for the plant communities. - J. Bot. 67: 15-22.

Huntley, B. and Birks, H. J. B. 1983. An atlas of past and present pollen maps for Europe: 0-13,000 years ago - Cambridge Univ. Press.

Hutchinson, G. E. 1957. A treatise on limnology Vol. I. - John Wiley and Sons.

Intergovernmental Panel on Climate Change Third Assessment Report. 2001a. Climate change 2001: impacts, adaptation and vulnerability. McCarthy, J. J., Canziani, O. F., Leary, N. A. (eds). - Cambridge Univ. Press.

Intergovernmental panel on climate change third assessment report. 2001b. Climate change 2001: The science of climate change. Houghton, J. T., Ding, Y., Griggs, D. J. (eds). - Cambridge Univ. Press.

Iwasaki, K. 1995. Factors delimiting the boundary between vertically contiguous mussel beds of Septifer virgatus (Wiegmann) and Hormomya mutabilis (Gould). - Ecol. Res. 10: 307-320.

Jablonski, D. 1987. Heritability at the species level: analysis of geographic ranges of Cretaceous mollusks. - Science 238: $360-363$.

Johnson, T., Dozier, J. and Michaelsen, J. 1999. Climate change and Sierra Nevada snowpack. - IAHS Publ. 256: 63-70.

Kareiva, P. M., Kingsolver, J. G. and Huey, R. B. (eds) 1993. Biotic interactions and global change. - Sinauer Associates.

Karl, T. R., Knight, R. W., Easterling, D. R. et al. 1996. Indices of climate change for the United States. - Bull. Am. Meteorol. Soc. 77: 279-292.
Kaufman, D. M. 1998. The structure of mammalian faunas in the New World: from continents to communities - Thesis, Univ. of New Mexico, Albuquerque, New Mexico, USA.

Kawecki, T. J. and Stearns, S. C. 1993. The evolution of life histories in spatially heterogeneous environments - optimal reaction norms revisited. - Evol. Ecol. 7: 155-174.

Keitt, T. H., Holt, R. D. and Lewis, M. 2001. Allee dynamics, invasion pinning, and species borders. - Am. Nat. 157: $203-216$.

Kindvall, O., Vessby, K., Berggren et al. 1998. Individual mobility prevents an Allee effect in sparse populations of the bush cricket Metrioptera roeseli: an experimental study. - Oikos 81: 449-457.

Kirkpatrick, M. and Barton, N. H. 1997. Evolution of a species' range. - Am. Nat. 150: 1-23.

Kuussaari, M., Saccheri, I., Camara, M. et al. 1998. Allee effect and population dynamics in the Glanville fritillary butterfly. - Oikos 82: 384-392.

Lewontin, R. C. and Birch, L. C. 1966. Hybridization as a source of variation for adaptation to new environments. - Evolution 20: 315-336.

Lind, H. 1994. Lepidoptera - important long-distance pollinators for plants in fragmented habitats. - Svensk Botanisk Tidskrift 88: 185-187.

Lovejoy and Hannah. (eds). in press. Climate change and biodiversity. Yale Univ. Press.

MacArthur, R. H. 1972. Geographical ecology. - Harper and Row.

MacArthur, R. H. and Wilson, E. O. 1967. The theory of island biogeography. - Princeton Univ. Press.

Mack, R. N. 1996. Predicting the identity and fate of plant invaders-emergent and everging approaches. - Biol. Conserv. 78: $107-121$.

Meehl, G. A., Karl, T. R., Easterling, D. R. et al. 2000a. An introduction to trends in extreme weather and climate events: observations, socioeconomic impacts, terrestrial ecological impacts, and model projections. - Bull. Am. Meteorol. Soc. 81: 413-416.

Meehl, G. A., Zwiers, F., Evans, J. et al. 2000b. Trends in extreme weather and climate events: issues related to modeling extremes in projection of future climate change. - Bull. Am. Meteorol. Soc. 81: 427-436.

Morgan, A. V. 1997. Fossil Coleoptera assemblages in the Great Lakes region of North America: past changes and future prospects. - In: Huntley, B., Cramer, W. and Morgan, A. V. (eds), Past and future rapid environmental changes: the spatial and evolutionary responses of terrestrial biota. Springer-Verlag, pp. 129-142.

Moyle, P. B. and Light, T. 1996. Fish invasions in California: do abiotic factors determine success? - Ecology 77: 1666-1670.

Muth, A. 1980. Physiological ecology of desert iguana (Dipsosaurus dorsalis) eggs: temperature and water relations. - Ecology 61: 1335-1343.

Myers, R. A., Barrowman, N. J., Hutchings, J. A. et al. 1995. Population dynamics of exploited fish stocks at low population levels. - Science 269: 1106-1108.

Nix, H. A. 1986. A biogeographic analysis of Australian elapid snakes. In: Longmore, R., (ed.), Atlas of Australian Elapid snakes. - Aust. Flora Fauna Ser. 8: 4-15.

Orton, J. H. 1920. Sea-temperature, breeding, and distribution in marine animals. - J. Mar. Biol. Ass. 12: 339-366.

Paine, R. T. 1977. Controlled manipulations in the marine intertidal zone, and their contributions to ecological theory. - Acad. Natl Sci., Spec. Publ. 12: 245-270.

Parmesan, C. 1996. Climate and species' range. - Nature 382: $765-766$

Parmesan, C. In press. Range and abundance changes. - In: Lovejoy, T. and Hannah, L. (eds), Climate change and biodiversity. Yale Univ. Press, ch. 9.

Parmesan, C. 2002. Detection of range shifts: general methodological issues and case studies using butterflies. - In: Walther, G.-R., Burga, C. A. and Edwards, P. J. (eds), Fingerprints of climate change: adapted behaviour 
and shifting species ranges. Kluwer Academic/ Plenum Publishers.

Parmesan, C. 2003. Butterflies as bio-indicators of climate change impacts. - In: Boggs, C. L., Watt, W. B. and Ehrlich, P. R. (eds), Evolution and ecology taking flight: butterflies as model systems. Univ. of Chicago Press.

Parmesan, C. and Yohe, G. 2003. A globally coherent fingerprint of climate change impacts across natural systems. - Nature 421: 37-42.

Parmesan, C. and Galbraith, H. 2004. Observed ecological impacts of climate change in North America, - Pew Foundation Report.

Parmesan, C., Ryrholm, N., Stefanescu, C. et al. 1999. Poleward shifts in geographical ranges of butterfly species associated with regional warming. - Nature 399: 579-583.

Parmesan, C., Root, T. L. and Willig, M. R. 2000. Impacts of extreme weather and climate on terrestrial biota. - Bull. Am. Meteorol. Soc. 81: 443-450.

Parsons, P. A. 1990. The metabolic cost of multiple environmental stresses: implications for climatic change and conservation. - Trends Ecol. Evol. 5: 315-317.

Pearson, R. G. and Dawson, T. P. 2003. Predicting the impacts of climate change on the distribution of species: are bioclimate envelope models useful? - Global Ecol. Biogeogr. 12: $361-371$.

Peters, R. L. and Lovejoy, T. E. (eds), 1992. Global warming and biological diversity. Yale Univ. Press.

Peterson, A. T. and Vargas, N. 1993. Ecological diversity in scrub jays, Aphelocoma coerulescens. - In: Ramamoorthy, T. P., Bye, R., Lot, A. et al. (eds), The biological diversity of Mexico: origins and distribution. Oxford Univ. Press, pp. 309-317.

Peterson, A. T. and Cohoon, K. P. 1999. Sensitivity of distributional prediction algorithms to geographic data completeness. - Ecol. Model. 117: 159-164.

Peterson, A. T., Soberón, J. and Sánchez-Cordero, V. 1999. Conservatism of ecological niches in evolutionary time. - Science 285: 1265-1267.

Ponel, P. 1997. The response of Coleoptera to late-Quaternary climate changes: evidence from north-east France. - In: Huntley, B., Cramer, W., Morgan, A. V. et al. (eds), Past and future rapid environmental changes: the spatial and evolutionary responses of terrestrial biota. Springer-Verlag, pp. $143-151$.

Pounds, J. A., Fogden, M. P. L. and Campbell, J. H. 1999. Biological response to climate change on a tropical mountain. - Nature 398: 611.

Rapoport, E. H. 1982. Areography: geographical strategies of species. - Pergammon Press.

Ricklefs, R. E. and and. Latham, R. E. 1992. Intercontinental correlation of geographical ranges suggests stasis in ecological traits of relict genera of temperate perennial herbs. - Am. Nat. 139: 1305-1321.

Rodríguez-Trelles, F. and Rodríguez, M. A. 1998. Rapid microevolution and loss of chromosomal diversity in Drosophila in response to climate warming. - Evol. Ecol. 12: 829-838.

Root, T. 1988a. Energy constraints on avian distributions and abundances. - Ecology 69: 330-339.

Root, T. 1988b. Environmental-factors associated with avian distributional boundaries. - J. Biogeogr. 15: 489-505.

Rosen, B. R. 1988. Biogeographic patterns: a perceptual overview. - In: Meyers, A. A. and Giller, P. S. (eds) Analytical biogeography. Chapman and Hall, pp. 23-55.

Roy, K., Jablonski, D. and Valentine, J. W. 1994. Eastern Pacific molluscan provinces and latitudinal diversity gradient: no evidence for "Rapoport's rule". - Proc. Natl Acad. Sci. 91: $8871-8874$.
Roy, K., Jablonski, D., Valentine, J. W. et al. 1998. Marine latitudinal diversity gradients: tests of causal hypotheses. - Proc. Natl Acad. Sci. 95: 3699-3702.

Sagarin, R. D., Barry, J. P., Gilman, S. E. et al. 1999. Climate related changes in an intertidal community over short and long time scales. - Ecol. Monogr 69: 465-490.

Salt, G. W. 1952. The relation of metabolism to climate and distribution in three finches of the genus Carpodacus. - Ecol. Monogr. 22: 121-152.

Sax, D. F. 1999. Native and exotic species distributions: implications for general models of diversity, from community to biogeographic scales. - Thesis, Univ. of New Mexico, Albuquerque, New Mexico, USA.

Sax, D. F., Gaines, S. D. and Brown, J. H. 2002. Species invasions exceed extinctions on islands world-wide: a comparative study of plants and birds. - Am. Nat. 160: $766-783$.

Schneider, S. H. 1993. Scenarios of global warming. - In: Kareiva, P. M., Kingsolver, J. G. and Huey, R. B. (eds), Biotic interactions and global change. Sinauer Associates, pp. 9-23.

Setchell, W. A. 1920. The temperature interval in the geographical distribution of marine algae. - Science 52: 187-190.

Simberloff, D. and Stiling, P. 1996. Risks of species introduced for biological control. - Biol. Conserv. 78: 185-192.

Singer, M. C. 1972. Complex components of habitat suitability within a butterfly colony. - Science 176: 75-77.

Singer, M. C. and Ehrlich, P. R. 1979. Population dynamics of the checkerspot butterfly Euphydryas editha. - Fortschritte Zool. 25: 53-60.

Singer, M. C. and Thomas, C. D. 1996. Evolutionary responses of a butterfly metapopulation to human and climate-caused environmental variation. - Am. Nat. 148: S9-S39.

Smith, F. A. and Betancourt, J. L. 1998. Response of bushytailed woodrats (Neotoma cinerea) to late Quaternary climatic change in the Colorado Plateau. - Quaternary Res. 50: 1-11.

Smith, F. A., Browning, H. and Shepherd, U. L. 1998. The influence of climate change on the body mass of woodrats Neotoma in an arid region of New Mexico, USA. - Ecography 21: 140 .

Smith, J. M. 1986. The problems of biology. - Oxford Univ. Press.

Southward, A. J., Hawkins, S. J. and Burrows, M. T. 1995. Seventy years' observations of changes in distribution and abundance of zooplankton and intertidal organisms in the western English Channel in relation to rising sea temperature. - J. Thermal Biol. 20: 127-155.

Stevens, G. C. 1989. The latitudinal gradient in geographic range: how so many species coexist in the tropics. - Am. Nat. 133: $240-256$.

Stevens, G. C. 1996. Extending Rapoport's rule to Pacific marine fishes. - J. Biogeogr. 23: 149-154.

Stockwell, D. R. B. and Noble, I. R. 1992. Induction of sets of rules from animal distribution data: a robust and informative method of data analysis. - Math. Comput. Simulation 32: $249-254$.

Tauber, M. J., Tauber, C. A. and Masaki, S. 1986. Seasonal adaptations of insects. - Oxford Univ. Press.

Taylor, P. and Gaines, S. D. 1999. Can Rapoport's rule be rescued? Modeling causes of the latitudinal gradient in species richness. - Ecology 80: 2474-2482.

Thomas, C. D. and Lennon, J. J. 1999. Birds extend their ranges northwards. - Nature 399: 213.

Thomas, C. D., Cameron, A., Green, R. E. et al. 2004. Extinction risk from climate change. - Nature 427: 145148.

Walther, G.-R., Post, E., Menzel, A. et al. 2002. Ecological responses to recent climate change. - Nature 416: 389-395. 
Webb, T. III and Bartlein, P. J. 1992. Global changes during the last 3 million years: climatic controls and biotic responses. - Annu. Rev. Ecol. Syst. 23: 141-173.

Weiss, S. B., Murphy, D. D. and White, R. R. 1988. Sun, slope, and butterflies: topographic determinants of habitat quality for Euphydras editha. - Ecology 69: 1486-1496.
Wethey, D. S. 1983. Geographic limits and local zonation: the barnacles Semibalanus (Balanus) and Chthamalus in New England. - Biol. Bull. 165: 330-341.

Wulff, E. V. 1950. An introduction to historical plant geography. - Chronica Botanica Company, Waltham, Massachusetts, USA. 